\title{
An easy technique to measure neo-chordae length during minimally invasive mitral valve repair
}

\author{
Minimal invaziv mitral kapak tamirinde neokorda boyu ölçümü için kolay bir teknik \\ Belhhan Akpınar ${ }^{1}$ (D), Mehmet Kerem Oral ${ }^{2}$ (D), Mehmet Ezelsoy² (1) \\ Institution where the research was done: \\ Istanbul Florence Nightingale Hospital, Istanbul, Turkey \\ Author Affiliations: \\ 'Department of Cardiovascular Surgery, Istanbul Florence Nightingale Hospital, Istanbul, Turkey \\ ${ }^{2}$ Department of Cardiovascular Surgery, Istanbul Bilim University, Istanbul, Turkey
}

\begin{abstract}
In this article, we present our experience with an easy and practical technique for measuring the length of neo-chordae during minimally invasive mitral valve repair. This technique is based on tying the knots at the level of the plane of the ring using a prolene suture passing through the transverse diameter of the ring as a guideline.

Keywords: Minimally invasive surgery, mitral valve repair, neochordae length.
\end{abstract}

Minimally invasive and robotic techniques have become increasingly popular for the treatment of mitral valve regurgitation. Surgical repair remains the gold standard today for nearly all patients with degenerative disease and for the majority of patients with other types of valvular disease. Current techniques include resection of prolapsed segment, neo-chordae implantation, and ring annuloplasty. ${ }^{[1]}$ Although techniques for resection of the prolapsed segment and implanting a ring are quite straightforward, the determination of an appropriate neo-chordae length remains intuitive and based on personal experience, particularly in minimally invasive and robotic cases. This difficulty explains why so many techniques such as premeasured chordae or different chordae measuring devices and special ring models have been proposed. ${ }^{[2,3]}$

\section{$\ddot{O} Z$}

Bu yazıda minimal invaziv mitral kapak tamiri sırasında neokorda uzunluğunu ölçmek için deneyimlerimiz kolay ve pratik bir teknik ile sunuldu. Bu teknik, bir kılavuz olarak, halkanın enine çapından geçen bir prolen sütür kullanılarak düğümleri, halka düzleminin seviyesine bağlanmasına dayanmaktadır.

Anahtar sözcükler: Minimal invaziv cerrahi, mitral kapak tamiri, neokorda boyu.

\section{SURGICAL TECHNIQUE}

Preoperative evaluation of the valve pathology with three-dimensional and transesophageal echocardiography (TEE) is mandatory. After a careful inspection of the valve, annuloplasty sutures are placed and a proper-sized ring is selected. Placing the annular sutures first enhances the exposure. Depending on the annular size, a 29 or 31-sized mechanical valve sizer is, then, introduced through the valve, until a clear view of both papillary muscles is achieved by folding down both leaflets into the ventricle (Figure 1). Subsequently, 4/0 polytetrafluoroethylene (PTFE) sutures are placed through the corresponding papillary muscle near the fibrous area. The sizer is taken out and the two free ends of the suture are guided out. The ring is, then, implanted. A coaptation line for the prolapsed leaflet

Received: November 30, 2019 Accepted: February 28, 2020 Published online: April 22, 2020

Correspondence: Mehmet Ezelsoy, MD. İstanbul Bilim Üniversitesi Kalp ve Damar Cerrahisi Anabilim Dalı, 34394 Şişli, İstanbul, Türkiye.

Tel: +90 533 - 4261797 e-mail: mehmet_ezelsoy@hotmail.com

Cite this article as:

Akpınar B, Oral MK, Ezelsoy M. An easy technique to measure neo-chordae length during minimally invasive mitral valve repair.

Turk Gogus Kalp Dama 2020;28(2):407-409 
is determined and marked by filling the left ventricle with saline. The neo-chordae stitches are passed from the ventricular to atrial side of the prolapsed leaflet edge through the marked line. To determine the appropriate length of the chorda, a $4 / 0$ prolene suture is passed through the transverse diameter of the ring at the level of the plane of the ring as a reference point (Figure 2). A loop is performed around this reference suture using both ends of the PTFE suture. Two or three initial loose knots are placed at this level, followed by seven or eight following knots (Figure 3).

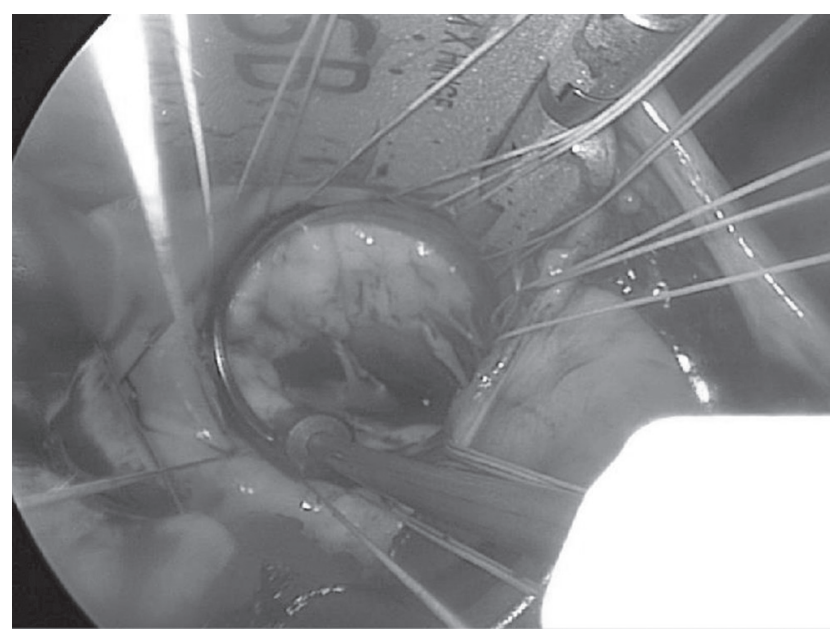

Figure 1. View of both papillary muscles via a mechanical valve sizer.

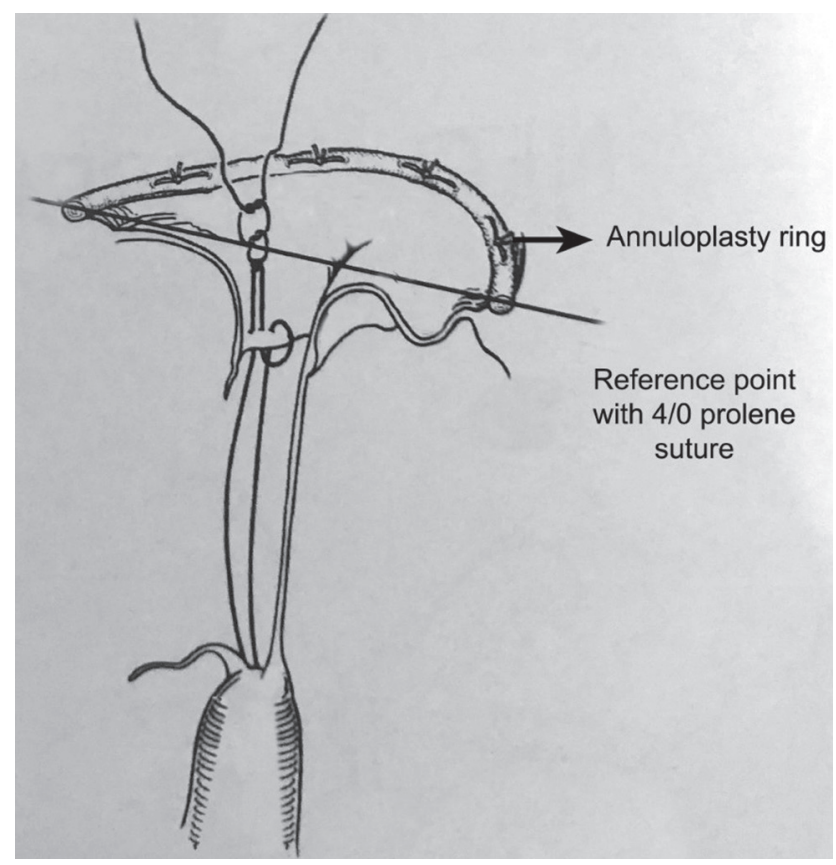

Figure 2. Schematic view of reference point with prolene suture.
The reference suture is, then, removed and the repair is completed. It is essential that the initial knots are tied loosely to avoid excessive tension on the GORE-TEX ${ }^{\circledR}$ suture and to prevent shortening of the neo-chordae and enhance the removal of the prolene guiding suture. Intraoperative TEE was used in all of the cases to assess the quality of the repair after cardiopulmonary bypass (CPB) (Figure 4). All patients underwent transthoracic echocardiography before hospital discharge to assess the quality of the repair and to evaluate whether there was postoperative residual regurgitation or stenosis.

\section{DISCUSSION}

The main difficulty using an artificial chorda in mitral valve repair is the adjustment of the length between the tip of the papillary muscle and leaflet edge. ${ }^{[4]}$ Not only is the adjustment difficult, but also the sliding character of PTFE thread make it difficult to tie knots, particularly in minimally invasive cases. These difficulties explain why so many techniques have been proposed for solving this problem until

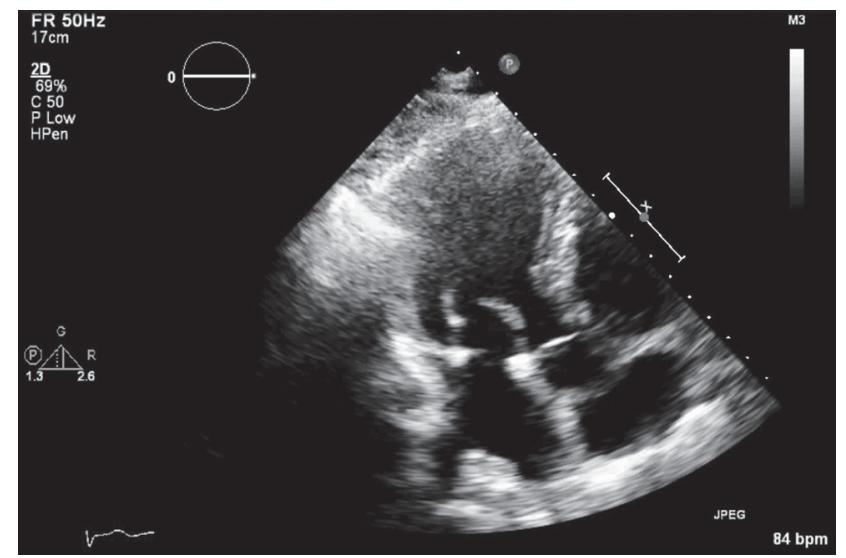

Figure 3. Tight and untight loop sutures around reference point.

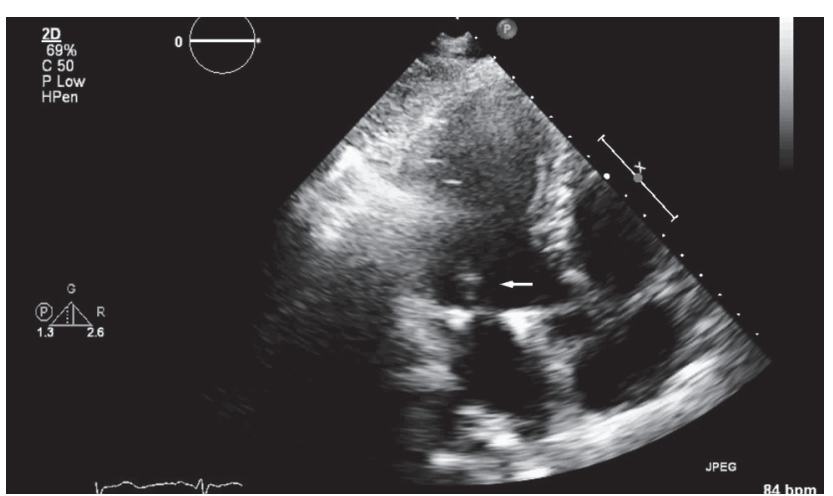

Figure 4. A postoperative echocardiographic image of neochordae (arrow). 
date. ${ }^{[3]}$ Besides various chordae measuring devices and pre-measured chordae, there are ring designs available with apparatuses to enhance the chorda length measurement (3D ReChord, Liva Nova PLC, London, UK). Whatever the technique chosen, the reference point method serves as the guideline for the adjustment of the length of the artificial chordae. Although there is usually at least one normal leaflet segment as a reference point opposite the prolapsed segment, this maneuver is much more difficult in minimally invasive and robotic cases.

The idea of tying the neo-chordae at the level of the plane of the ring was first suggested by Carlos Duran, MD in cases without reference point. ${ }^{[5]}$ Since this can be also difficult in minimally invasive cases, we created a visible reference point by putting a stitch through the transverse diameter and at the level of the plane of the ring. One can suggest that there is a contradiction between tying knots at the plane of the ring, while it is known that the coaptation point is well below the plane of the annulus. This may be explained by the fact that implantation of the ring automatically reduces the aorto-mitral angle, the anterior mitral leaflet annulus angle, and excursion of the anterior mitral leaflet. This is probably why moderate degrees of anterior mitral leaflet prolapse can be solely solved by annuloplasty. ${ }^{[6]}$

Tying the neo-chordae at the level of the plane of the ring has been used by Duran over a decade. Indeed, such a reference point was present in the early generation of Duran rings, which is not available today. The method described above can be used in all ring models and can be applied in both anterior and posterior prolapse and Barlow's disease.

Based on our experiences, 54 cases were performed using this technique during a four-year period. All repairs were performed using a right mini-thoracotomy with endoscopic assistance. Early postoperative TEE in the operating room revealed none or trivial mitral regurgitation in 52 cases (Figure 3). In two cases, CPB had to be re-established to repair clefts causing moderate regurgitation. At discharge, all patients had no $(n=52)$ or trivial $(n=2)$ mitral regurgitation. During follow up for about two to 48 months, one patient was reoperated for endocarditis and six were lost-to-follow-up. Among 47 remaining patients, 45 had no mitral regurgitation and two had trivial-to-moderate mitral regurgitation. Our results are consistent with the literature. ${ }^{[7,8]}$

In conclusion, based on our experiences, making the level of the annulus with a suture has offered us an easy, reproducible, and reliable option in these cases on both conventional, minimally invasive, and robotic cases after having tried many different techniques.

\section{Declaration of conflicting interests}

The authors declared no conflicts of interest with respect to the authorship and/or publication of this article.

\section{Funding}

The authors received no financial support for the research and/or authorship of this article.

\section{REFERENCES}

1. Cohn LH, Tchantchaleishvili V, Rajab TK. Evolution of the concept and practice of mitral valve repair. Ann Cardiothorac Surg 2015;4:315-21.

2. Prinzing A, Bleiziffer S, Krane M, Lange R. Initial Experience With a New Mitral Ring Designed to Simplify Length Determination of Neochords. Ann Thorac Surg 2018;105:1784-9.

3. von Oppell UO, Mohr FW. Chordal replacement for both minimally invasive and conventional mitral valve surgery using premeasured Gore-Tex loops. Ann Thorac Surg 2000;70:2166-8.

4. Carpentier A. Cardiac valve surgery--the "French correction". J Thorac Cardiovasc Surg 1983;86:323-37.

5. Duran CM. Surgical techniques for the repair of anterior mitral leaflet prolapse. J Card Surg 1999;14:471-81.

6. Varnous S, Acar C, Leprince P, Bounet N, Lansac E, Pavie A, et al. Effect of prosthetic ring annuloplasty on mitral leaflet motion. An Echocardiographic Study. Eur Heart J 2002;4(Suppl):737.

7. Onan B, Erkanlı K, Onan İS, Ersoy B, Aktürk İF, Bakır I. Clinical outcomes of mitral valve repair: a singlecenter experience in 100 patients. Turk Gogus Kalp Dama 2014;22:19-28.

8. Salihi S, Güden M. Durability of mitral valve repair: A single center experience. Turk Gogus Kalp Damar Cerrahisi Derg 2019;27:459-68. 